\title{
Changes in circulating immune complex concentrations and antibody titres during treatment of $\mathrm{Q}$ fever endocarditis
}

\author{
PV COYLE, ${ }^{*}$ J THOMPSON, $\dagger$ AAJ ADGEY, $\ddagger$ DA RUTTER,, A FAY, $\dagger$ TA MCNEILL, $\dagger$ \\ JH CONNOLLY* \\ From the ${ }^{*}$ Regional Virus Laboratory, and the $¥$ Regional Medical Cardiology Centre, Royal Victoria \\ Hospital, Belfast, the $\dagger$ Department of Microbiology and Immunobiology, Queen's University of Belfast, \\ Belfast, and the \$Public Health Laboratory Service Centre for Applied Microbiology and Research, Porton \\ Down, Salisbury, Wiltshire
}

SUMMARY Serum samples from 20 patients with $Q$ fever endocarditis were tested for the presence of circulating immune complexes to see whether their concentrations correlated with antibody titres during treatment and whether they could be used to monitor the response to antimicrobial treatment. Circulating immune complexes were found in all 20 patients. The concentrations in 15 patients correlated with either or both of the $Q$ fever phase 1 and phase 2 antibody titres obtained during treatment. In the other five patients no correlation with the antibody titres was found. There was no association between circulating immune complex concentrations and clinical response to treatment.

Coxiella burnetii is endemic in the British Isles and is a cause of infection world wide. Although once thought to be a rare cause of endocarditis, this organism now accounts for up to $3 \%$ of all cases reported in England and Wales. ${ }^{1}$ In Northern Ireland there have been 24 cases of chronic $Q$ fever endocarditis between 1974 and 1985.

$C$ burnetii undergoes phase variation and can therefore express two different antigens: phase 1 and phase 2. Usually, in acute infections antibodies to the phase 2 antigen only are produced, and circulating immune complexes can also be detected. ${ }^{2}$ In chronic infections antibodies to both the phase antigens are produced. Varma $e t \mathrm{al}^{3}$ have shown that chronic $Q$ fever endocarditis can be monitored during treatment by serial measurement of phase 1 and phase 2 antibody titres. We have investigated retrospectively 20 cases of chronic $Q$ fever endocarditis treated in $\mathbf{N}$ Ireland over the past nine years to see whether circulating immune complexes were present and whether their concentrations correlated with the $\mathrm{Q}$ fever antibody response during treatment.

Accepted for publication 2 April 1985

\section{Material and methods}

Phase 1 and phase 2 titres were measured throughout the course of treatment in the 20 patients using the complement fixation technique described by Bradstreet and Taylor ${ }^{4}$; the antigens and antisera were supplied by the Division of Microbiological Reagents and Quality Control, Central Public Health Laboratory, London. Antibody titres are expressed as reciprocals. Serum samples from the patients were stored at $-20^{\circ} \mathrm{C}$ and used subsequently to look for the presence of circulating immune complexes, which were measured by the Raji cell radioimmunoassay. ${ }^{5}$ Values were expressed as micrograms of aggregated human gammaglobulin equivalent (AHG eq) per millilitre of serum. Values below $50 \mu \mathrm{gAHGeq} / \mathrm{ml}$ are of doubtful importance.

To assess variation between runs for a given serum while using the Raji cell assay a panel of normal and circulating immune complex positive samples were routinely included for testing on separate runs.

Identification of $C$ burnetii in the vegetations was carried out in three patients by inoculating suspensions of the heart valves into guineapigs. Serum samples taken from the guineapig before and after 
inoculation were tested for $\mathrm{Q}$ fever complement fixing antibody.

\section{Results}

$Q$ fever endocarditis was diagnosed in the 20 patients on the basis of the clinical findings and the presence of high antibody titres against $Q$ fever phase 1 and phase 2 antigens.

Once the diagnosis had been confirmed antimicrobial treatment was started, using a combination of trimethoprim and sulphamethoxazole and oxytetracycline; rifampicin was substituted for oxytetracycline in patient 3 . Treatment continued until the patient's phase 1 antibody titre fell to $<200$.

The Table shows the type of circulating immune complex response in each case, the duration of antimicrobial treatment, and whether the endocarditis occurred on a natural or prosthetic heart valve. The maximum circulating immune complex value detected in each patient is also included.

Two types of circulating immune complex response were noted during treatment. Fifteen patients showed type 1 responses, with the circulating immune complex concentration correlating with at least one of the antibody phase titres during treatment (Fig. 1). Fig. 2, which shows the response of patient 14, has been included in the type 1 category because of correlation between the circulating immune complex concentrations and the phase 1 antibody titres only; this was particularly striking during the break in chemotherapy that occurred dur-

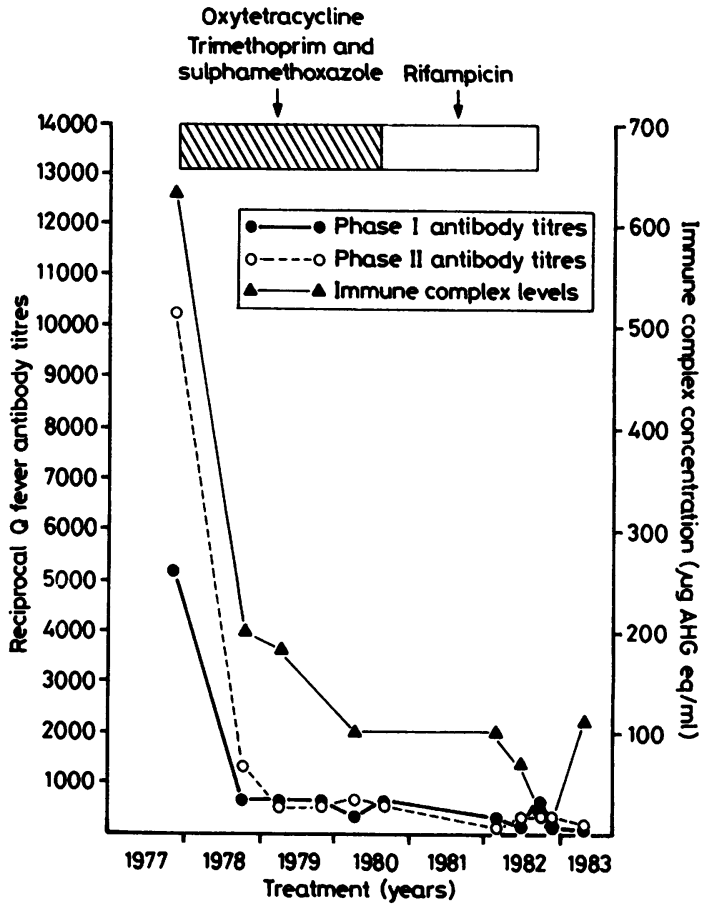

Fig. 1 Changes in $Q$ fever antibody titre and circulating immune complex concentration in patient 3 during treatment.

ing treatment. The remaining five patients had type 2 responses, with circulating immune complex val-

Type and peak values of circulating immune complex responses in 20 treated patients with $Q$ fever endocarditis

\begin{tabular}{|c|c|c|c|c|c|c|c|}
\hline $\begin{array}{l}\text { Patient } \\
\text { no }\end{array}$ & Sex & Age & $\begin{array}{l}\text { Duration of } \\
\text { antimicrobial } \\
\text { treatment }\end{array}$ & $\begin{array}{l}\text { Period from } \\
\text { valve operation } \\
\text { to endocarditis }\end{array}$ & $\begin{array}{l}\text { Type of } \\
\text { response }\end{array}$ & $\begin{array}{l}\text { No of } \\
\text { specimens }\end{array}$ & $\begin{array}{l}\text { Maximum } \\
\text { circulating immune } \\
\text { complex value } \\
(\mu g A H G e q / m l) \ddagger\end{array}$ \\
\hline $\begin{array}{r}1 \\
2 \\
3 \\
4 \\
5 \\
6 \\
7 \\
8 \\
9 \\
10 \\
11 \\
12 \\
13 \\
14 \\
15 \\
16 \\
17 \\
18 \\
19 \\
20\end{array}$ & $\begin{array}{l}\mathbf{F} \\
\mathbf{M} \\
\mathbf{M} \\
\mathbf{F} \\
\mathbf{F} \\
\mathbf{F} \\
\mathbf{F} \\
\mathbf{M} \\
\mathbf{F} \\
\mathbf{F} \\
\mathbf{M} \\
\mathbf{M} \\
\mathbf{M} \\
\mathbf{M} \\
\mathbf{F} \\
\mathbf{M} \\
\mathbf{M} \\
\mathbf{F} \\
\mathbf{F} \\
\mathbf{F}\end{array}$ & $\begin{array}{l}56 \\
58 \\
37 \\
50 \\
33 \\
57 \\
69 \\
47 \\
64 \\
64 \\
71 \\
67 \\
61 \\
40 \\
40 \\
33 \\
25 \\
51 \\
40 \\
33\end{array}$ & 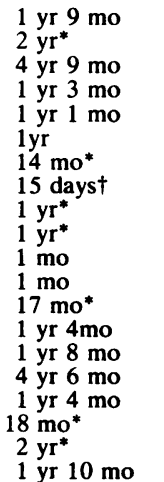 & $\begin{array}{l}\text { Natural valves } \\
\text { Natural valves } \\
9 \mathrm{yr} \\
2 \mathrm{yr} \\
7 \mathrm{yr} \\
4 \mathrm{yr} \\
\text { Natural valves } \\
5 \mathrm{mo} \\
9 \mathrm{yr} \\
\text { Natural valves } \\
\text { Natural valves } \\
6 \mathrm{mo} \\
3 \mathrm{yr} \\
2 \mathrm{yr} \\
2 \mathrm{yr} \\
\mathrm{Natural} \text { valves } \\
2 \mathrm{mo} \\
7 \mathrm{yr} \\
12 \mathrm{yr} \\
6 \mathrm{yr}\end{array}$ & $\begin{array}{l}1 \\
1 \\
1 \\
1 \\
1 \\
1 \\
1 \\
1 \\
1 \\
1 \\
1 \\
1 \\
1 \\
1 \\
1 \\
1 \\
1 \\
2 \\
2 \\
2 \\
2 \\
2\end{array}$ & $\begin{array}{r}7 \\
8 \\
9 \\
7 \\
7 \\
11 \\
15 \\
1 \\
3 \\
4 \\
2 \\
2 \\
7 \\
9 \\
11 \\
9 \\
6 \\
8 \\
13 \\
7\end{array}$ & $\begin{array}{r}630 \\
1258 \\
630 \\
312 \\
630 \\
1120 \\
630 \\
500 \\
125 \\
112 \\
500 \\
790 \\
200 \\
200 \\
200 \\
28 \\
35 \\
89 \\
125 \\
125\end{array}$ \\
\hline
\end{tabular}

*Patient's antimicrobial treatment continuing at time of writing.

†Patient died during the early stages of treatment.

¥Micrograms of aggregated human gammaglobulin equivalent per millilitre of serum. 


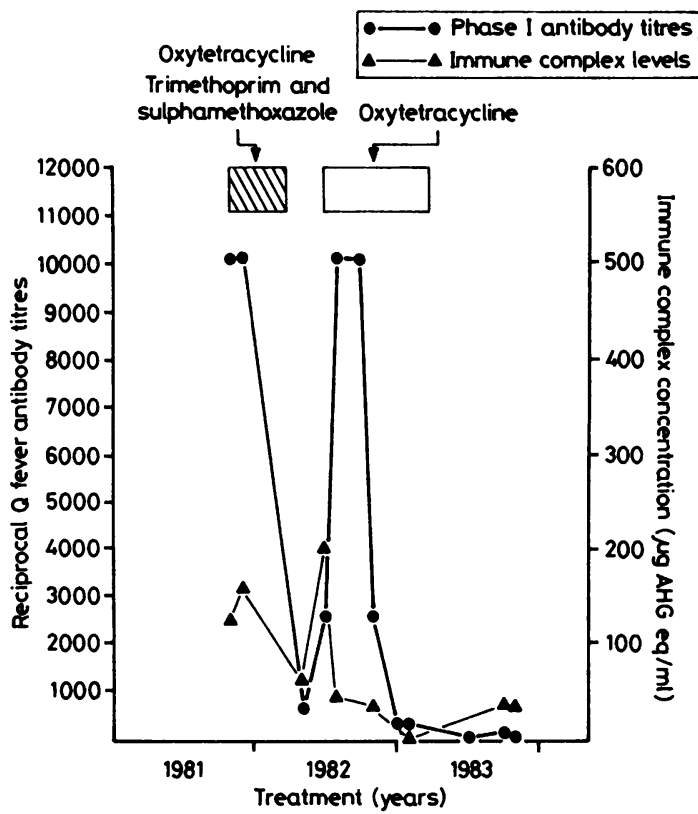

Fig. 2 Changes in $Q$ fever phase 1 antibody titre and circulating immune complex concentration in patient 14 during treatment.

ues showing no correlation with either phase 1 or phase 2 antibody titres.

$C$ burnetii organisms were present on the aortic valves removed from three patients $(7,8$, and 19$)$, two of whom (patients 8 and 19) had prosthetic valves. A significant rise in $Q$ fever antibody titre was found in the guineapig serum after inoculation of the suspension of heart valves.

The panel of normal and circulating immune complex positive samples tested in different Raji cell assay runs showed no significant changes in their recorded values.

\section{Discussion}

All patients with $Q$ fever endocarditis in Northern Ireland are monitored during treatment by repeated assays of their phase 1 and phase 2 antibody titres. Our results are interesting in that we were able, over several years in some patients, to compare the phase 1 and phase 2 antibody response with the circulating immune complex concentrations in these 20 patients. In most of our patients circulating immune complexes became undetectable before the patient's antimicrobial treatment was stopped-that is, when the phase 1 titre fell to $<200$. Whether circulating immune complex values are a more accurate reflection of continuing infection is difficult to say, but the fact that five patients had low and unpredict- able concentrations would leave this in doubt. Fig. 1 shows that patient 3's circulating immune complex value had risen to $112 \mu \mathrm{gHAGeq} / \mathrm{ml}$ one year after stopping all chemotherapy with no evidence of clinical relapse and no increase in his $Q$ fever antibody titres. The significance of this rise is uncertain.

Neither antibody nor circulating immune complex values could be used to monitor the day to day clinical response of the patients as symptomatic improvement usually took place rapidly after the start of antimicrobial treatment. Their main use was to act as an indicator of the continuing infection in the early months of treatment, despite the apparent clinical well being of the patient. This point is demonstrated in patient 14: when treatment stopped for 3 months the patient's clinical condition deteriorated and his phase 1 antibody and circulating immune complex values rose considerably (Fig. 2). On restarting antimicrobial treatment, clinical improvement was soon followed by a fall in circulating immune complex values and phase 1 antibody titres.

Other workers have suggested a similar role for circulating immune complexes in bacterial endocarditis infections. Bayer $e^{2} a^{b}$ found that high circulating immune complex concentrations correlated with the extravalvular manifestations of the disease. Effective treatment resulted in the elimination of circulating immune complexes, usually within six weeks of starting chemotherapy. Kauffman et al found that higher circulating immune complex values resulted from prolonged endocardial infection with less virulent bacteria. Pocidalo et al,${ }^{8}$ however, found no correlation between circulating immune complex concentrations and clinical presentation of the disease, nor a fall in values with antimicrobial treatment. They concluded that the duration of the illness determined the extent of circulating immune complex production. This observation would account for the high circulating immune complex values seen in most of our patients. It does not explain the association between the circulating immune complexes and antibody titres during treatment in 15 of the 20 patients. The detection of low and unpredictable concentrations of circulating immune complexes in the five other patients might be due to transient production or a more efficient clearing system as a result of individual differences in the immune response. It is also possible that the antigenic structure of the organism may be different in these patients.

$C$ burnetii can be isolated from the blood in $\mathrm{Q}$ fever endocarditis before the start of antimicrobial treatment. ${ }^{9}$ Whether the presence of viable organisms in the blood has any effect on the production of circulating immune complexes is uncertain. 
The eradication of $C$ burnetii with antimicrobial treatment, associated with a fall in circulating immune complex concentrations and phase 1 and phase 2 antibody titres, suggests that the antigenic component of the complexes may come from the organism. Fig. 2 shows that the circulating immune complex response follows the phase 1 antibody titres more closely, which suggests that phase 1 antigen may be present in the complexes. Alternatively, rheumatoid factor is present in patients with chronic $Q$ fever endocarditis ${ }^{10}$ and may also form part of the circulating immune complexes we have detected in this study.

The serum samples tested in this study had been stored at $-20^{\circ} \mathrm{C}$ for varying periods. There are no reports on the effect of serum storage on results obtained with the Raji cell radioimmunoassay; nor have we formally examined the effect of multiple freeze and thaw cycles or different storage temperatures on test samples. We discount significant deterioration for several reasons. Several circulating immune complex positive samples that are routinely included in our clinical runs have been tested repeatedly for periods of up to one year, with no significant variation or evidence of deterioration. Our standard curve samples for the Raji cell assay are stored for up to one year before a new lot is prepared. New and old lots give assay read outs that are parallel and almost superimposed. Also Julkunen et $a l^{\text {" }}$ reported that prolonged serum storage at $-20^{\circ} \mathrm{C}$ did not significantly affect the results obtained using a $\mathrm{C} 1 \mathrm{q}$ binding enzyme linked immunosorbent immune complex assay. While different tests for immune complexes probably measure different things, the results obtained using a $\mathrm{C} 1 \mathrm{q}$ binding assay and a Raji cell assay are highly comparable. ${ }^{12}$

We thank Mervyn Killen for his assistance in preparing the graphic material.

\section{References}

' Palmer SR, Young SEJ. Q-fever endocarditis in England and Wales, 1975-81. Lancet 1982; ii: 1448-9.

${ }^{2}$ Lumio J, Penttinen K, Petterson T. Q-fever in Finland: clinical, immunological and epidemiological findings. Scand $J$ Infect Dis 1981;13:17-21.

${ }^{3}$ Varma MPS, Adgey AAJ, Connolly JH. Chronic Q-fever endocarditis. Br Heart J 1980;43:695-9.

${ }^{4}$ Bradstreet CMP, Taylor CED. Technique of complementfixation test applicable to the diagnosis of virus diseases. Monthly Bulletin of the Ministry of Health and the Public Health Laboratory Service 1962; i:547-52.

$s$ Theofilopolos AN, Wilson CB, Dixon FJ. The Raji cell radioimmunoassay for detecting immune-complexes in human serum. J Clin Invest 1976;57:169-82.

- Bayer AS, Theofilopolos AN, Eisenberg R, Dixon LB. Circulating immune complexes in infective endocarditis. $N$ Engl $J$ Med 1976;295: 1500-5.

${ }^{7}$ Kauffman RH, Thompson J, Valentijn RM, Dalia Mr, Van Es LA. The clinical implications and the pathogenic significance of circulating immune complexes in infective endocarditis. $\mathrm{Am}$ J Med 1981;71:17-25.

${ }^{8}$ Pocidalo MA, Gibert C, Verroust P, et al. Circulating immune complexes and severe sepsis: duration of infection as the main determinant. Clin Exp Immunol 1982;47:513-9.

' Andrews PS, Marmion MA. Chronic Q-fever. Br Med J 1959;ii:985-8.

1" Peacock MG, Philip RN, Williams JC, Faulkner RS. Serological evaluation of $Q$-fever in humans: enhanced phase 1 titres of immunoglobulins $G$ and $A$ are diagnostic for $Q$-fever endocarditis. Infect Immun 1983;41:1089-98.

" Julkunen I, Lindstorn P, Wager O, Lenttinen K. Immune complex assays and stored normal human sera. J Immunol Methods 1983;56: 167-74.

${ }^{12}$ Lambert PH, Dixon FJ, Zubler R, et al. A WHO collaborative study for the evaluation of eighteen methods for detecting immune complexes in serum. J Clin Lab Immunol 1978; 1:115.

Requests for reprints to: Dr PV Coyle, Regional Virus Laboratory, Royal Victoria Hospital, Belfast BT12 6BN, Northern Ireland. 